No. $12-4$

\title{
Investment in Customer Recognition and Information Exchange
}

\author{
Oz Shy and Rune Stenbacka
}

\begin{abstract}
:
We investigate how costly acquisition and exchange of customer-specific information affects industry profit and consumer welfare. Consumers differ in their preferences for competing brands and in their switching costs between brands. Brand-producing firms use their acquired knowledge of customer-specific preferences to differentiate prices. We show that consumers are worse off when firms acquire information about their preferences and that information sharing between firms further magnifies their losses. No information sharing supports a subgame perfect equilibrium that is also efficient. Finally, equilibrium investments in customer information may be excessive if firms bear low costs of acquiring customer-specific information.
\end{abstract}

Keywords: customer recognition, preference recognition, price discrimination, exchange of information, switching costs

JEL Classifications: D4, D82, L1, L4

Oz Shy is a senior economist in the research department of the Federal Reserve Bank of Boston. His e-mail address is oz.shy@bos.frb.org. Rune Stenbacka is a professor of economics at the Hanken School of Economics in Helsinki. His e-mail address is rune.stenbacka@hanken.fi.

This paper, which may be revised, is available on the web site of the Federal Reserve Bank of Boston at http://www.bostonfed.org/economic/wp/index.htm.

We thank Suzanne Lorant, Ali Ozdagli, Staffan Ringbom, Scott Schuh, and Bob Triest for valuable suggestions and comments on earlier drafts.

The views and opinions expressed in this paper are those of the authors and do not necessarily represent the views of the Federal Reserve Bank of Boston or the Federal Reserve System.

This version: February 15, 2012 


\section{Introduction}

In some industries, an established customer relationship makes it possible for a firm to learn the individual characteristics of its customers, thereby facilitating individualized pricing. This may be particularly true in service industries, with banking and insurance as prominent examples. In industries like these, firms often design institutions to facilitate the exchange of such customerspecific information. In this study we analyze the effects of the exchange of customer-specific information on industry profits and consumer welfare, as well as firms' incentives to invest in learning their customers' preferences.

Consumers may benefit from information exchange among firms because it facilitates the design of aggressive poaching offers (price cuts intended to lure a consumer to switch brands). For example, a consumer originally mismatched with a higher preference for a rival brand would benefit from a poaching offer that is sufficiently competitive to compensate for the switching costs. On the other hand, within the framework of an established customer relationship an incumbent firm facing competition from a rival firm seeking to poach its customers by targeting them with differential pricing offers based on their type-specific preferences can also adjust its own typecontingent prices to existing customers so as to maximize the extraction of consumer surplus. Thus, general economic intuition is insufficient to evaluate the effects of the exchange of customerspecific information on industry profits and consumer surplus, and therefore an analytical study is needed.

In practice, although a firm might be able to distinguish its own inherited customers from those of its rival at a relatively low or even negligible cost, the cost of acquiring information about the preferences of its customers is significantly higher. Therefore, the firm faces the optimization problem of whether to acquire customer-specific information to facilitate setting individualized prices, or whether to set prices contingent only on whether it has an established customer relationship with the consumer. In addition, the incentives to acquire customer-specific information depend crucially on whether the firms have committed themselves to a system of information exchange. Our model is designed to investigate this relationship.

In this study we design a duopoly model with consumers differentiated by their switching 
costs. Each consumer holds an individual valuation (high or low) for the two competing brands. We begin by characterizing firms' incentives to invest in learning the idiosyncratic valuations of the firms' customers regarding the competing brands and we investigate how these incentives are affected by the costs of acquiring information. We establish that both firms invest in information acquisition when the costs of information gathering are sufficiently low, whereas neither firm invests when the information gathering costs are sufficiently high. When investment costs are in an intermediate range, both firms invest in learning their customers' preferences only if this information is not exchanged between the firms. We show that the exchange of acquired customerspecific information harms industry profits.

Most importantly, we characterize the welfare consequences of the exchange of customerspecific information. Our first conclusion in this respect is that acquiring and using information regarding customer-specific preferences as a basis for type-contingent pricing always hurts consumers. We show that information sharing between firms magnifies the loss to consumer welfare even further. We frame the set of decisions facing firms that are considering whether to engage in customer-information acquisition and use as a three-stage game with the following sequence of decisions: (1) each firm decides whether or not to share customer-related information, (2) each firm decides whether or not to invest in information acquisition, and (3) firms engage in price competition, and we conduct an equilibrium analysis of this game. We establish that the case of no information sharing supports a subgame perfect equilibrium for such a three-stage game. Furthermore, we demonstrate that the equilibrium with no information sharing is efficient from the point of view of total welfare. Finally, we demonstrate that the market equilibrium supports excessive investment in information acquisition for a low investment cost.

Our study is related to an important research approach focusing on evaluating the effects of information exchange in oligopolies. This approach is exemplified in Shapiro (1986) and Gal-Or $(1985,1986)$. This literature typically focuses on evaluating the consequences of sharing exogenous information regarding production costs or demand conditions. The effects of information exchange typically depend on the type of uncertainty (demand or cost uncertainty, industrywide or firm-specific) as well as on the mode of competition (Bertrand or Cournot competition). In contrast 
to this literature, we evaluate the effects of information exchange with respect to customer-specific information under circumstances where the acquisition of costly information is endogenized. In models where firms endogenously determine the precision of the acquired information, Kirby (2004), Jansen (2008), and Ganuza and Jansen (2010) explore the effects of exchanging information regarding demand or cost conditions under Cournot competition. However, these studies do not analyze the effects of information exchange with customer-specific information. With a focus on credit markets and with an emphasis on industry-specific features, Pagano and Jappelli (1993), Padilla and Pagano (1997), and Gehrig and Stenbacka (2007) study the incentives of banks to exchange information regarding the creditworthiness of individual clients. However, these studies do not explore these incentives under circumstances where the banks optimize with respect to the precision of the credit tests based on their investments in information acquisition.

Our study is importantly linked to the literature on behavior-based or history-based price discrimination, with Fudenberg and Tirole (2000) as a seminal contribution. In the absence of information acquisition, firms base their pricing decisions only on their knowledge of whether they have an established relationship with a particular consumer. In the presence of differentiated switching costs, history-based pricing of this type was originally analyzed by Chen (1997). ${ }^{1}$ If a firm acquires information regarding the brand valuations of its customers, it can apply individualized prices for its inherited customers. In the absence of information sharing, this configuration yields an informational advantage because the rival has no information as a basis for setting typecontingent poaching offers. In line with Shin and Sudhir (2010), such informational advantages constitute a strong incentive for firms to invest in customer-specific information.

Information exchange eliminates informational advantages and therefore enlarges the set of price instruments available for type-specific consumer poaching. From this perspective, information exchange generally intensifies competition, in line with the intuition developed in the influential model of Thisse and Vives (1988). Thisse and Vives (1988) compares competition based on completely individualized prices with competition based on uniform prices within the framework of a

\footnotetext{
${ }^{1}$ Taylor (2003), Esteves (2010), Gabrielsen (2004), Chen and Zhang (2009), Gehrig and Stenbacka (2004), and Gehrig, Shy, and Stenbacka (2011) are examples of subsequent studies that have applied related approaches for analyzing history-based pricing. Fudenberg and Villas-Boas (2007) and Esteves (2009) present extensive literature surveys on behavior-based price discrimination.
} 
Hotelling model. Liu and Serfes (2006) study a two-period model, where firms can engage in perfect price discrimination in the second period. They demonstrate that the firms' incentives to sell customer-specific information to each other depend on the distribution of the inherited customer bases. Furthermore, they show that consumers always suffer from information exchange when evaluated over the two-period horizon, even though consumers benefit in the second period. Also, Shy and Stenbacka (2011) studies how exogenously-determined customer recognition affects price competition. In contrast to these studies, the present paper endogenizes firms' decisions to invest in customer recognition and explores the effects of sharing this information among rival firms within such a framework. In addition, the present analysis also evaluates the performance of strategic information sharing with the feature that the decision whether to share information is integrated into the firm's overall business strategy.

Liu and Serfes (2004) and Chen, Narasimhan, and Zhang (2001) design duopoly models of price discrimination where firms have imperfect customer-specific information. Within such a framework these studies characterize the relationship between the precision of the information and the equilibrium profits associated with discriminatory pricing based on this information. Contrary to these studies, we analyze the effects of information exchange under circumstances where the firms optimize their investments in customer recognition and where, ultimately, the decision whether to engage in information exchange is integrated into the firms' overall business strategies.

Our study proceeds as follows. Section 2 sets up the model. Section 3 investigates firms' incentives to acquire information about the preferences of their own customers, assuming that firms engage in industrywide information sharing of the collected information, with a particular emphasis on the effects of information exchange on consumers. Section 4 conducts the same investigation, assuming that banks do not share any information about their customers' preferences. Section 5 compares firms' incentives to acquire information when information is shared and when it is not. Section 6 conducts a welfare analysis. Section 7 endogenizes firms' decisions on whether to share information. Section 8 concludes with policy implications. 


\section{The Model}

Two firms, indexed by $i=A, B$, produce differentiated brands of goods or services. We make the following assumption.

ASSUMPTION 1. Each consumer buys exactly one unit of either brand A or brand B, but not both, to maximize a utility function to be defined below.

Let $v=\left(v_{A}, v_{B}\right) \in \mathbb{R}_{+}^{2}$ denote a consumer's benefit from buying brand $A$ and from buying brand $B$, respectively, where $v_{i} \in\left\{v_{L}, v_{H}\right\}, i=A, B$. Assuming $v_{H}>v_{L}>0$, define $\Delta \stackrel{\text { def }}{=} v_{H}-v_{L}$ as the difference between these two valuations. Therefore, there are four categories of consumer: Type $\left(v_{H}, v_{H}\right)$ places equally high value on brand $A$ and $B$; type $\left(v_{H}, v_{L}\right)$ values brand $A$ higher than $B$; type $\left(v_{L}, v_{H}\right)$ values brand $B$ higher than $A$; and type $\left(v_{L}, v_{L}\right)$ places equally low value on both brands.

Each of the four consumer categories described above is composed of a continuum of potential customers who are uniformly indexed by $s$ on the unit interval $[0,1]$ according to their cost of switching from one brand to the other. Let $p_{A}$ denote the price that firm $A$ offers to consumers who have purchased brand $A$ before, and $q_{A}$ the price offered to consumers who earlier purchased brand $B$ (the competing brand). Firm $B^{\prime}$ s prices, $p_{B}$ and $q_{B}$, are defined analogously. We interpret $p_{A}$ and $p_{B}$ as the incumbency prices to loyal customers, whereas $q_{A}$ and $q_{B}$ are poaching prices intended to induce switching from the firm with which the consumer has an established customer relationship.

It is necessary to assume heterogeneous switching costs in order to model circumstances where some customers remain loyal to their incumbent supplier, whereas other customers switch to the rival supplier. The utility of a consumer with preference $\left(v_{A}, v_{B}\right)$, switching cost $s(s \in[0,1])$, and 
an established customer relationship with firm $A$ is defined by

$$
U_{A}\left(s ; v_{A}, v_{B}\right) \stackrel{\text { def }}{=} \begin{cases}v_{H}-p_{A}^{H H} & \text { high preference for both brands, and continues to buy } A \\ v_{H}-p_{A}^{H L} & \text { high preference for } A, \text { low for } B, \text { and continues to buy } A \\ v_{L}-p_{A}^{L H} & \text { low preference for } A \text {, high for } B, \text { and continues to buy } A \\ v_{L}-p_{A}^{L L} & \text { low preference for both brands, and continues to buy } A \\ v_{H}-q_{B}^{H H}-\sigma s & \text { high preference for both brands, and switches to } B \\ v_{L}-q_{B}^{H L}-\sigma s & \text { high preference for } A, \text { low for } B, \text { and switches to } B \\ v_{H}-q_{B}^{L H}-\sigma s & \text { low preference for } A \text {, high for } B, \text { and switches to } B \\ v_{L}-q_{B}^{L L}-\sigma s & \text { low preference for both brands, and switches to } B .\end{cases}
$$

The parameter $\sigma>0$ measures the intensity of the switching costs, in the sense that high values of $\sigma$ generate higher switching cost differentiation across buyers $s \in[0,1]$. Brand-producing firms are aware of the distribution of switching costs, but they are not able to obtain any information about the switching costs of individual consumers. The utility of a consumer with an inherited customer relationship with firm $B$, denoted by $U_{B}\left(s ; v_{A}, v_{B}\right)$, is defined in an analogous way. To obtain interior equilibria, we assume the following:

ASSUMPTION 2. Some consumers have switching costs that exceed the differences in consumers' valuations. Formally, $\sigma>3\left(v_{H}-v_{L}\right)=3 \Delta$.

The utility function (1) captures the benchmark configuration where both firms are able to recognize the preferences of all consumers in the economy. Such a structure with maximal information would emerge when both firms decide to acquire customer-specific information regarding their own customers, and also decide to exchange that information with their rival. In such a configuration, firm $A$ is able to set type-specific incumbency prices $\left(p_{A}^{H H}, p_{A}^{H L}, p_{A}^{L H}, p_{A}^{L L}\right)$, and firm $B$ sets type-specific poaching prices $\left(q_{B}^{H H}, q_{B}^{H L}, q_{B}^{L H}, q_{B}^{L L}\right)$. Firm $B^{\prime}$ s incumbency prices and firm $A^{\prime}$ s poaching prices are similarly defined.

If both firms invest in order to acquire information regarding customer-specific preferences of their customer base and if both firms exchange this information, then the utility function (1) defines eight switching cost thresholds describing the consumers who are indifferent between staying loyal to their brand supplier and switching to the competing brand. Formally, these 
indifference conditions are defined by

$$
\begin{aligned}
v_{H}-p_{A}^{H H}=v_{H}-q_{B}^{H H}-\sigma s_{A}^{H H} & v_{H}-p_{B}^{H H}=v_{H}-q_{A}^{H H}-\sigma s_{B}^{H H} \\
v_{H}-p_{A}^{H L}=v_{L}-q_{B}^{H L}-\sigma s_{A}^{H L} & v_{L}-p_{B}^{H L}=v_{H}-q_{A}^{H L}-\sigma s_{B}^{H L} \\
v_{L}-p_{A}^{L H}=v_{H}-q_{B}^{L H}-\sigma s_{A}^{L H} & v_{H}-p_{B}^{L H}=v_{L}-q_{A}^{L H}-\sigma s_{B}^{L H} \\
v_{L}-p_{A}^{L L}=v_{L}-q_{B}^{L L}-\sigma s_{A}^{L L} & v_{L}-p_{B}^{L L}=v_{L}-q_{A}^{L L}-\sigma s_{B}^{L L} .
\end{aligned}
$$

To explain (2), first notice that the left column describes brand $A$ customers, who are indifferent between repurchasing (staying loyal to) brand $A$ and switching to brand $B$. The right column captures brand $B$ customers, who are indifferent between repurchasing brand $B$ and switching to brand $A$. For a detailed interpretation, let us focus on, for example, the third indifference condition in the right column. The left-hand side of this equation denotes the utility of a brand $B$ customer with a low valuation for brand $A$ and a high valuation for brand $B$. If such a customer repurchases brand $B$, his utility is $v_{H}-p_{B}^{L H}$. If, alternatively, this buyer switches to $A$, the utility becomes $v_{L}-q_{A}^{L H}-\sigma s_{B}^{L H}$, where $q_{A}^{L H}$ is firm $A^{\prime}$ s type-contingent poaching price. In this equation, $s_{B}^{L H}$ is the switching cost threshold, above which customers stay loyal to $B$ and below which customers switch to $A$.

Solving equations (2) with respect to the switching cost thresholds of the $4 \times 2$ consumer groups (4 different consumer types, each having an inherited customer relationship split between two brands), we obtain

$$
\begin{aligned}
s_{A}^{H H} & =\frac{p_{A}^{H H}-q_{B}^{H H}}{\sigma} & s_{B}^{H H} & =\frac{p_{B}^{H H}-q_{A}^{H H}}{\sigma} \\
s_{A}^{H L} & =\frac{p_{A}^{H L}-q_{B}^{H L}-\Delta}{\sigma} & s_{B}^{H L} & =\frac{p_{B}^{H L}-q_{A}^{H L}+\Delta}{\sigma} \\
s_{A}^{L H} & =\frac{p_{A}^{L H}-q_{B}^{L H}+\Delta}{\sigma} & s_{B}^{L H} & =\frac{p_{B}^{L H}-q_{A}^{L H}-\Delta}{\sigma} \\
s_{A}^{L L} & =\frac{p_{A}^{L L}-q_{B}^{L L}}{\sigma} & s_{B}^{L L} & =\frac{p_{B}^{L L}-q_{A}^{L L}}{\sigma} .
\end{aligned}
$$


Let $c$ denote the investment cost that each firm must incur in order to learn about the customerspecific preferences of its own customers. Then, the profit function of firm $A$ is given by

$$
\begin{aligned}
\pi_{A}=p_{A}^{H H}\left(1-s_{A}^{H H}\right)+p_{A}^{H L}\left(1-s_{A}^{H L}\right)+p_{A}^{L H}(1- & \left.s_{A}^{L H}\right)+p_{A}^{L L}\left(1-s_{A}^{L L}\right) \\
& \quad+q_{A}^{H H} s_{B}^{H H}+q_{A}^{H L} s_{B}^{H L}+q_{A}^{L H} s_{B}^{L H}+q_{A}^{L L} s_{B}^{L L}-c .
\end{aligned}
$$

The first row in (4) is the profit that firm $A$ earns from "loyal" buyers with switching costs above the switching cost thresholds. The profit from loyal customers can be decomposed into four terms, one for each type of consumer with an inherited customer relationship with firm $A$. The second row in (4) is the profit that firm $A$ earns from poaching, whereby some of the customers with an inherited customer relationship with $B$ decide to switch. More precisely, $A$ 's poaching offers attract those of $B^{\prime}$ s customers who have switching costs below the threshold defined in (3). The second row in (4) shows that the poaching profits can also be decomposed into four terms, one for each type of switching consumers belonging to $B^{\prime}$ s inherited segment. The profit of firm $B$ is similarly defined according to

$$
\begin{aligned}
\pi_{B}=p_{B}^{H H}\left(1-s_{B}^{H H}\right)+p_{B}^{H L}\left(1-s_{B}^{H L}\right)+p_{B}^{L H}(1- & \left.s_{B}^{L H}\right)+p_{B}^{L L}\left(1-s_{B}^{L L}\right) \\
& +q_{B}^{H H} s_{A}^{H H}+q_{B}^{H L} s_{A}^{H L}+q_{B}^{L H} s_{A}^{L H}+q_{B}^{L L} s_{A}^{L L}-c .
\end{aligned}
$$

Firms have access to a technology for acquiring information regarding the specific preferences of those of their customers with whom they have formed a customer relationship. This information acquisition is modeled in the simplest possible way: By investing $c$ the firm learns the type of all its customers. ${ }^{2}$ Sections 3 and 4 analyze two-stage games in which firms decide whether to invest in information acquisition prior to the subsequent stage of price competition. Section 3 assumes that the firms are committed to exchanging information, whereas in Section 4 firms do not share any information about their customers' preferences. Thus, Sections 3 and 4 investigate how a given information sharing strategy affects the returns on information acquisition and thereby the firms' incentives to invest in acquiring information. These results are later used in Section 7 to endogenize firms' decisions whether or not to exchange their available information.

\footnotetext{
${ }^{2}$ This assumption is introduced primarily for reasons of tractability. Nevertheless the assumption seems to be a reasonably good description of situations where firms make use of fixed investments in information technology as a device to facilitate customer recognition so that the marginal costs associated with an additional customer are negligible.
} 


\section{Investing in Preference Recognition: Information Sharing}

In this section we focus on a regime where the firms are committed to exchanging information, and we characterize the equilibrium investment in information acquisition. In the presence of information sharing, each firm faces the following dilemma. On one hand, information acquisition permits each firm to extract higher surplus from its own customers by differentiating prices according to preferences. On the other hand, this information will be shared with the rival firm, which can use this information to differentiate its poaching prices.

\subsection{Both firms invest in preference recognition}

Suppose that each firm invests $c$ in acquiring information. Doing so enables each firm to recognize the preferences of its own customers. Since the firms share all their information, each firm can engage in price discrimination among all types of consumers (its own customers and those of the competing firm). In other words, each firm can direct type-contingent incumbency prices to customers belonging to its inherited market segment, and can also target type-contingent poaching prices to consumers who have a customer relationship with the rival firm. Technically, substituting (3) into (4), firm $A$ maximizes profit (4) by choosing eight prices, four prices for its former customers $\left(p_{A}^{H H}, p_{A}^{H L}, p_{A}^{L H}, p_{A}^{L L}\right)$ and four poaching prices targeted to $B^{\prime}$ s customers $\left(q_{A}^{H H}, q_{A}^{H L}, q_{A}^{L H}\right.$, $\left.q_{A}^{L L}\right)$. Similarly, substituting (3) into (5), firm $B$ maximizes profit (5) by choosing eight prices: $p_{B}^{H H}$, $p_{B}^{H L}, p_{B}^{L H}, p_{B}^{L L}$, and $q_{B}^{H H}, q_{B}^{H L}, q_{B}^{L H}, q_{B}^{L L}$.

The Nash-Bertrand equilibrium prices to loyal customers are

$$
p_{A}^{H H}=p_{B}^{H H}=p_{A}^{L L}=p_{B}^{L L}=\frac{2 \sigma}{3}, \quad p_{A}^{H L}=p_{B}^{L H}=\frac{2 \sigma+\Delta}{3}, \quad \text { and } \quad p_{A}^{L H}=p_{B}^{H L}=\frac{2 \sigma-\Delta}{3} .
$$

The Nash-Bertrand equilibrium poaching prices are

$$
q_{A}^{H H}=q_{B}^{H H}=q_{A}^{L L}=q_{B}^{L L}=\frac{\sigma}{3}, \quad q_{A}^{H L}=q_{B}^{L H}=\frac{\sigma+\Delta}{3}, \quad \text { and } \quad q_{A}^{L H}=q_{B}^{H L}=\frac{\sigma-\Delta}{3} .
$$

The first four prices in (6) and (7) target consumers who have equal valuations for the brands $A$ and $B$. For these prices with symmetric valuations, a comparison of (6) and (7) reveals that the incumbency prices are double the poaching prices. This difference is a manifestation of the 
effects of switching costs, yielding the result that incumbency prices exceed poaching prices in equilibrium. The four prices on the right-hand side of (6) and (7) correspond to consumers who have unequal valuations for the brands $A$ and $B$. These prices show that firms charge a premium for the consumer's favorite brand and similarly apply a brand discount to consumers with low preference for the brand.

Substituting the equilibrium prices (6) and (7) into (3) and then into (4) and (5), the equilibrium profits when both firms invest in customer recognition and share all this information is given in the (Invest, Invest) entry in Table 1. This equilibrium profit is an increasing function of the differentiation with respect to the switching costs $(\sigma)$ as well as of the valuation difference $(\Delta)$.

Firm $B$

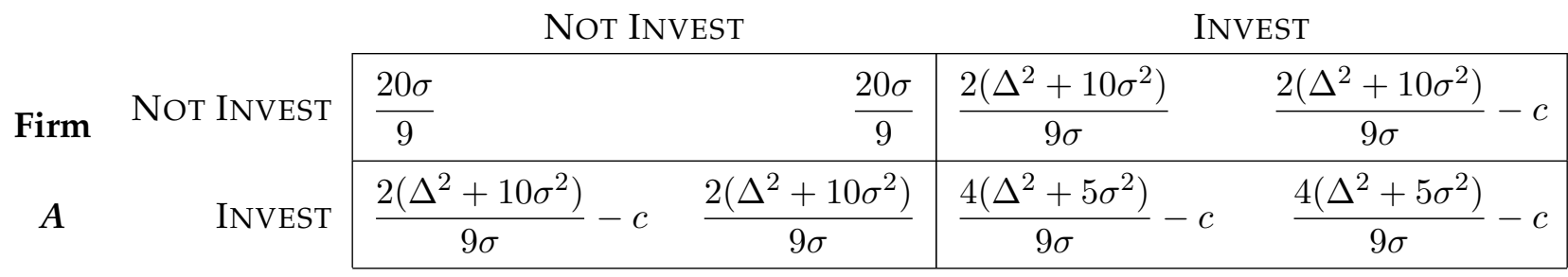

Table 1: Investment in recognition of own customer preferences: Profits under information sharing.

\subsection{Neither firm invests in preference recognition}

Now consider the opposite configuration, in which no firm invests in customer recognition. With no information acquisition neither firm can distinguish among consumer types. Therefore, there is no basis for information exchange. With no ability to distinguish among customer types, each firm is restricted to setting prices conditional only on its knowledge about the customers' purchase history, that is, with which firm each consumer has an established customer relationship. Thus, each firm sets two prices, an incumbency price for its own inherited customers and a poaching price targeted to the rival's customers.

Formally, each firm $i=A, B$ now sets $p_{i} \stackrel{\text { def }}{=} p_{i}^{H H}=p_{i}^{H L}=p_{i}^{L H}=p_{i}^{L L}$ and $q_{i} \stackrel{\text { def }}{=} q_{i}^{H H}=q_{i}^{H L}=$ $q_{i}^{L H}=q_{i}^{L L}$. Thus, firm $A$ chooses $p_{A}$ and $q_{A}$ to maximize (4), and firm $B$ chooses $p_{B}$ and $q_{B}$ to 
maximize (5). The equilibrium prices are given by

$$
p_{A}=p_{B}=\frac{2 \sigma}{3} \quad \text { and } \quad q_{A}=q_{B}=\frac{\sigma}{3} .
$$

These prices coincide with those derived in the model of history-based price discrimination by Chen (1997). Substituting these prices into the market share thresholds (3), and then into the profit functions (4) and (5) and setting $c=0$, because neither firm invests in preference recognition, yields the equilibrium profits that are displayed in the upper-left quadrant of Table 1.

\subsection{Asymmetric equilibrium: Only one firm invests in preference recognition}

Consider now an asymmetric equilibrium of the following type. Assume that firm $A$ invests in preference recognition and consequently knows the preferences of all its customers and that it shares this information with firm $B$, whereas firm $B$ does not recognize the preferences of its customers. Therefore, information sharing allows firm $B$ to free-ride on $A$ 's investment in customer recognition, whereas firm $A$ does not obtain any information regarding $B^{\prime}$ s customers, because firm $B$ simply has no information to share. With full information regarding $A$ 's customers, firm $A$ sets type-contingent prices $p_{A}^{H H}, p_{A}^{H L}, p_{A}^{L H}, p_{A}^{L L}$. Likewise, with information sharing, firm $B$ targets type-contingent poaching prices $q_{B}^{H H}, q_{B}^{H L}, q_{B}^{L H}, q_{B}^{L L}$ to $A^{\prime}$ s customers. For customers belonging to $B$ 's segment, firm $A$ sets a uniform poaching price $q_{A}$ and firm $B$ charges a uniform incumbency price $p_{B}$. Substituting these prices into (3) and then into the profit functions (4) and (5), the Nash-Bertrand equilibrium prices are found to be

$$
\begin{array}{r}
p_{B}=p_{A}^{H H}=p_{A}^{L L}=\frac{2 \sigma}{3}, \quad p_{A}^{H L}=\frac{2 \sigma+\Delta}{3}, \quad p_{A}^{L H}=\frac{2 \sigma-\Delta}{3}, \quad q_{A}=q_{B}^{H H}=q_{B}^{L L}=\frac{\sigma}{3}, \\
q_{B}^{H L}=\frac{\sigma-\Delta}{3}, \quad \text { and } \quad q_{B}^{L H}=\frac{\sigma+\Delta}{3} .
\end{array}
$$

Substituting (9) into (4) and (5), with $c=0$ for firm $B$ only, yields the equilibrium profits on the lower-left quadrant of Table 1. With this configuration both firms collect identical revenues, because they possess the same information about $A^{\prime}$ s and $B^{\prime}$ s customers. However, firm $B$ freerides on the information collected and shared by firm $A$ and hence avoids the cost associated with information acquisition. Finally, the upper-right quadrant of Table 1 is obtained in a similar way 
by changing the roles played by $A$ and $B$ (letting firm $B$ invest in customer recognition and share it with firm $A$ ).

\subsection{Equilibrium investment when information is shared}

The analysis so far has computed the equilibrium profits associated with the four different outcomes of firms' investment decisions under the assumption that firms share all the information they have. The equilibrium profits, summarized in Table 1, define a normal-form game in which each firm chooses whether to invest in learning the preferences of its customers. Comparing profits in Table 1 implies that $A$ invests given that firm $B$ does not invest if $c \leq 2 \Delta^{2} /(9 \sigma)$. Likewise, firm $A$ invests given that firm $B$ invests also if $c \leq 2 \Delta^{2} /(9 \sigma)$. Hence, the asymmetric investment equilibrium described in subsection 3.3 does not exist. We can now state the following result.

Result 1. For a sufficiently low cost of information acquisition, both firms invest in preference recognition of their own customers. Formally, under information sharing, (Invest, Invest) constitutes the unique Nash equilibrium of the game displayed in Table 1 if $c \leq 2 \Delta^{2} /(9 \sigma)$. For a sufficiently high cost, $c>2 \Delta^{2} /(9 \sigma)$, the unique equilibrium involves no investment in customer recognition.

The condition on low cost given in Result 1 can also be interpreted as sufficiently high brand differentiation as reflected by the difference $\Delta=v_{H}-v_{L}$, or as an upper bound on the switching cost parameter, $\sigma$.

\section{Investing in Preference Recognition: Information Is Not Shared}

Section 3 assumes that the firms have committed to share all the information they have regarding the preferences of their customers. This section analyzes the firms' incentives to invest in learning their customers' preferences when they do not share any information.

\subsection{Symmetric investment equilibria}

There are two symmetric equilibria: (No Invest, No Invest) and (Invest, Invest). The no investment equilibrium is identical to the one analyzed in subsection 3.2, because if firms do not invest, they simply do not have any information to share regarding their customers' preferences. Hence, the 
equilibrium prices (9) apply and the equilibrium profit levels in the upper-left quadrant of Table 1 are now copied to Table 2.

Firm $B$

\begin{tabular}{|c|c|c|c|c|c|}
\hline \multirow[b]{2}{*}{ Firm } & \multirow[b]{2}{*}{ Not INVEST } & \multicolumn{2}{|c|}{ NOT INVEST } & \multicolumn{2}{|c|}{ INVEST } \\
\hline & & $\frac{20 \sigma}{9}$ & $\frac{20 \sigma}{9}$ & $\frac{20 \sigma}{9}$ & $\frac{9 \Delta^{2}+40 \sigma^{2}}{18 \sigma}-c$ \\
\hline$A$ & INVEST & $\frac{9 \Delta^{2}+40 \sigma^{2}}{18 \sigma}-c$ & $\frac{20 \sigma}{9}$ & $\frac{9 \Delta^{2}+40 \sigma^{2}}{18 \sigma}-c$ & $\frac{9 \Delta^{2}+40 \sigma^{2}}{18 \sigma}-c$ \\
\hline
\end{tabular}

Table 2: Investment in own customer recognition: Profits when information is not shared.

We proceed to the second symmetric equilibrium where both firms invest in order to collect information regarding their own customers, but do not share this information with the rest of the industry. Knowing the preferences of its customers, firm $A$ sets five prices, $p_{A}^{H H}, p_{A}^{H L}, p_{A}^{L H}, p_{A}^{L L}$ and $q_{A}$, to maximize its profit (4). However, firm $A$ is restricted to a single uniform poaching price targeted to $B^{\prime}$ s customers, because firm $B$ does not disclose the information it has collected regarding its own customers. Similarly, firm $B$ sets five prices to maximize (5): $p_{B}^{H H}, p_{B}^{H L}, p_{B}^{L H}, p_{B}^{L L}$, and $q_{B}$. The Nash-Bertrand equilibrium prices are

$$
\begin{aligned}
p_{A}^{H H}=p_{B}^{H H}=p_{A}^{L L}=p_{B}^{L L}=\frac{2 \sigma}{3}, \quad p_{A}^{H L}=p_{B}^{L H}=\frac{4 \sigma+3 \Delta}{6} & \\
& p_{A}^{L H}=p_{B}^{H L}=\frac{4 \sigma-3 \Delta}{6}, \quad \text { and } q_{A}=q_{B}=\frac{\sigma}{3} .
\end{aligned}
$$

The incumbency prices and poaching prices associated with equal valuations coincide with those derived in the model of history-based price discrimination by Chen (1997), and these prices are largely determined by the switching costs. With unequal valuations for the brands $A$ and $B$ the incumbency prices are modified to incorporate a brand premium for the consumer's favorite brand, and similarly a brand discount for the less preferred brand. Substituting (10) into the market share thresholds (3) and then into (4) and (5) yields the equilibrium profit levels exhibited on the lower-right quadrant of Table 2. 


\subsection{Asymmetric investment equilibrium}

Using derivations similar to that in subsection 3.3, we also analyze the asymmetric configuration, where firm $A$ invests to learn the preferences of its customers, whereas firm $B$ does not make such an investment. However, unlike in subsection 3.3, firm $A$ does not share the information acquired with firm $B$. Therefore, under this information asymmetry, firm $A$ maximizes (4) by deciding on type-contingent incumbency prices, $p_{A}^{H H}, p_{A}^{H L}, p_{A}^{L H}, p_{A}^{L L}$, as well as on a uniform poaching price, $q_{A}$. Firm $B$, having access to any type-contingent information, maximizes (5) with only two price instruments: $p_{B}$ and $q_{B}$. Solving these two profit-maximization yields the price equilibrium

$$
p_{B}=p_{A}^{H H}=p_{A}^{L L}=\frac{2 \sigma}{3}, \quad p_{A}^{H L}=\frac{4 \sigma+3 \Delta}{6}, \quad p_{A}^{L H}=\frac{4 \sigma-3 \Delta}{6}, \quad q_{A}=q_{B}=\frac{\sigma}{3} .
$$

Substituting the equilibrium prices (11) into (3) and then into (4) and (5) yields the equilibrium profit levels exhibited in the lower-left quadrant of Table 2. The equilibrium profits in the upperright quadrants can be constructed in the same way.

\subsection{Equilibrium investment when information is not shared}

As in subsection 3.4, we can make use of the profit levels in Table 2 to characterize the Nash equilibrium with respect to the investment decisions with no information sharing. Following the same approach as that leading to Result 1, we can now state the following result.

Result 2. For a sufficiently low cost of information acquisition, both firms invest in preference recognition of their customers. Formally, in the absence of information sharing, (Invest, Invest) is the unique Nash equilibrium of the game displayed in Table 2 if $c \leq \Delta^{2} /(2 \sigma)$. For a sufficiently high cost, $c>\Delta^{2} /(2 \sigma)$, the unique equilibrium exhibits no investment in customer recognition.

\section{Incentives to Recognize Customer Preferences}

Results 1 and 2 derive the cost thresholds below which the firm has incentives to invest in information acquisition with and without information sharing, respectively. Based on a comparison of Results 1 and 2 we can conclude that the incentives to acquire customer-specific information depend 
crucially on whether the firms share this information or not. We can characterize the effects of information exchange on the incentives to invest in information acquisition as follows.

Result 3. If the cost of acquiring information, $c$, is

(a) low (formally, $c<2 \Delta^{2} /(9 \sigma)$ ), then both firms invest in learning their customers' preferences;

(b) intermediate (formally, $2 \Delta^{2} /(9 \sigma) \leq c \leq \Delta^{2} /(2 \sigma)$ ), then both firms invest in learning their customers' preferences only if information is not shared between the firms;

(c) high (formally, $c>\Delta^{2} /(2 \sigma)$ ), then neither firm acquires information.

Figure 1 illustrates Result 3.

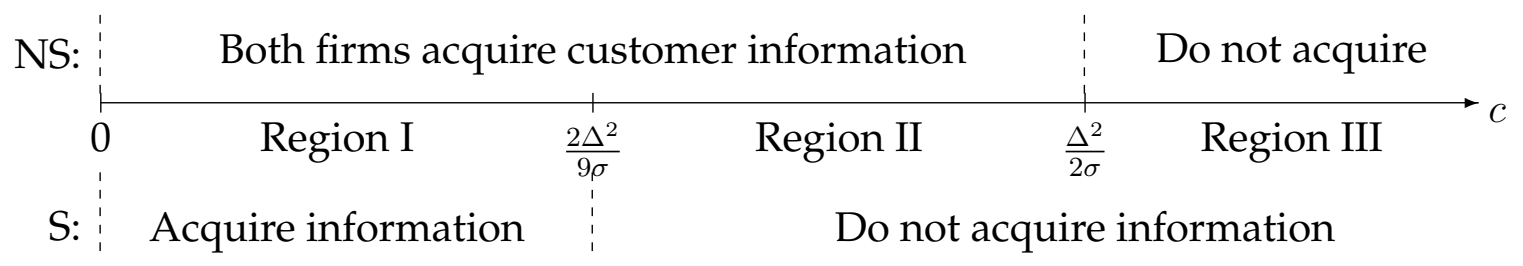

Figure 1: Incentives to acquire customer-specific information as a function of costs, $c$. NS: No information sharing between firms. S: Information sharing.

Technically, Result 3 demonstrates that information sharing lowers the cost threshold below which firms find it profitable to acquire information. Thus, information sharing reduces firms' incentives to acquire customer-specific information. This result is not self-evident, because information sharing has advantages as well as disadvantages for a firm engaged in competition. On the negative side, information sharing offers a free-riding opportunity to the rival and therefore reduces the returns associated with information acquisition. That is, information sharing makes it possible for the rival to design type-contingent poaching offers, which diminish the profit associated with the firm's type-contingent incumbency prices. On the positive side, with information sharing the firm can benefit from the rival's acquired information regarding the preferences of its customers. This makes it possible for the firm to enhance its poaching profits by designing type-contingent poaching offers. Combining the two effects, Result 3 demonstrates that the negative effect dominates the positive effect. In other words, the loss imposed on the incumbency profit by the rival's type-contingent poaching offers exceeds the benefit associated with poaching activities that are 
based on the information provided by the rival firm.

Result 3 means that the incentives to acquire customer-specific information depend on the associated costs and on whether the firms have committed themselves to an information sharing arrangement. Empirically, the costs of acquiring customer-specific information could very well differ across different categories of customers. For example, in their extensive empirical study of information exchange in the banking industry, Jappelli and Pagano (2002) emphasize that the information required to assess the creditworthiness of firms is likely to be more complex and less standardized than for individuals. Relatedly, the empirical study by Brown, Jappelli, and Pagano (2009) of information exchange between banks in transition countries suggests that the benefits from information sharing might be particularly high in countries with weak company law and weak creditor rights.

\section{Welfare Implications}

This section evaluates the effects of information exchange on consumer welfare, industry profits, and total welfare. Section 7 below endogenizes firms' decisions to exchange information. However, for the purpose of the welfare analysis in this section, the decision whether to share information is treated exogenously. We conduct a comparison among outcomes under two separate assumptions: Information is shared and information is not shared. This approach has the merit of providing a robust framework to assess the gains and losses from information sharing, and thereby identifies the winners and losers from information sharing, regardless of how the decisions to share information are reached. Such an evaluation of information exchange could be relevant for policymakers and regulators.

We conduct a welfare comparison among the symmetric outcomes associated with three regimes: (i) firms acquire information and share information, denoted (S,I); (ii) firms acquire information, but do not share information, denoted (NS,I); and (iii) no information acquisition (NI). Note that for regime (NI) it is irrelevant whether firms share information or not, because the firms have no information to share if they do not invest in learning their customers' preferences. For each outcome, we assume that firms subsequently engage in price competition as described in previous 
sections.

\subsection{Analysis of switching consumers}

In each of the eight consumer groups (four consumer categories multiplied by two because they may start as $A$ or $B$ customers), consumers with low switching costs change brands, whereas consumers with high switching costs remain loyal. The number of consumers who switch brands is computed from the eight thresholds defined in (3) based on substitution of the equilibrium prices corresponding to the above-described three configurations of information acquisition and information sharing.

A particularly interesting feature of our model is that some consumers respond to aggressive poaching offers, which induce them to switch to their less-preferred brand. We will adopt the following terminology.

DEFINITION 1. Let the number of switching consumers be determined by (3). We say that switching is Inefficient: if consumers switch from their preferred brand (yielding basic utility $v_{H}$ ) to their less-preferred brand (yielding basic utility $v_{L}$ ).

Efficient: if consumers switch from their less-preferred brand (yielding basic utility $v_{L}$ ) to their preferred brand (yielding basic utility $v_{H}$ ).

Neutral: if the basic utility of consumers does not change as a result of their switching brands.

In view of (3), the number of consumers who switch inefficiently, denoted by $T^{I}$, and efficiently, denoted by $T^{E}$, is

$$
T^{I}=s_{A}^{H L}+s_{B}^{L H} \quad \text { and } \quad T^{E}=s_{A}^{L H}+s_{B}^{H L},
$$

respectively. Thus, there are $s_{A}^{H L}$ consumers who switch from $A$ (ideal brand) to $B$ (less preferred brand) and $s_{B}^{L H}$ who switch from $B$ (ideal brand) to brand $A$ (less preferred). Table 3 displays the number of switching consumers $T^{I}$ and $T^{E}$ for the three information configurations (S,I), (NS,I), and (NI). These numbers are computed by substituting the equilibrium prices (6) and (7), (10), and (8), respectively into (3).

The following results turn out to be very important for interpreting the welfare results derived in the remainder of this section. 


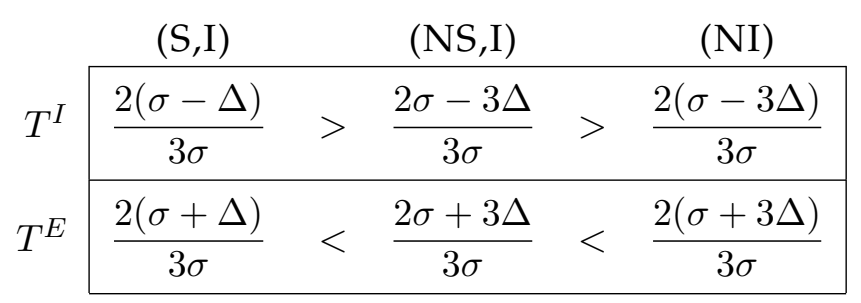

Table 3: Number of inefficiently switching consumers $\left(T^{I}\right)$ and efficiently switching consumers $\left(T^{E}\right)$, under the three possible symmetric outcomes: (S,I), (NS,I), and (NI).

Result 4. Customer-specific information acquisition by firms increases the number of consumers who engage in inefficient switching and reduces the number of consumers who engage in efficient switching. Furthermore, information exchange magnifies these effects. Formally, $T^{I}(S, I)>T^{I}(N S, I)>T^{I}(N I)$ and $T^{E}(S, I)<T^{E}(N S, I)<T^{E}(N I)$.

Result 4 highlights the main distortion caused by information acquisition, a distortion that is further intensified when the firms share their acquired information. Increased information regarding customer-specific preferences enables the firms to refine the precision of their poaching prices. In particular, firms reduce poaching prices for those consumers who prefer their brand less, to lure them into abandoning their most preferred brand. This practice promotes inefficient switching.

\subsection{Analysis of profits}

Table 4 combines Table 1 and Table 2 in order to calculate industry profits for the possible combinations of information exchange and information acquisition. The right-hand column of Table 4 shows that profits do not vary based on whether or not firms exchange information, because no information has been acquired in the first place. Further, by comparing the entries in the left-hand column of Table 4 we can directly conclude that the exchange of acquired information always reduces industry profits.

Table 4 yields the following result, which summarizes the effects of information acquisition and information exchange on industry profits.

Result 5. Industry profits among the three outcomes associated with possible combinations of information 


\begin{tabular}{|c|c|c|}
\hline & ACQUIRE INFORMATION (I) & NOT ACQUIRE INFO. (NI) \\
\hline$S$ & $\frac{8 \Delta^{2}+40 \sigma^{2}}{9 \sigma}-2 c$ & $\frac{40 \sigma}{9}$ \\
\hline NS & $\frac{9 \Delta^{2}+40 \sigma^{2}}{9 \sigma}-2 c$ & $\frac{40 \sigma}{9}$ \\
\hline
\end{tabular}

Table 4: Industry profit $\left(\Pi=\pi_{A}+\pi_{B}\right)$ under the three possible symmetric outcomes: (S,I), (NS,I) and (NI).

sharing and investment in information acquisition are ranked as follows:

$$
\begin{aligned}
& \Pi(N S, I)>\Pi(S, I)>\Pi(N I) \quad \text { if } \quad c<\frac{4 \Delta^{2}}{9 \sigma}, \\
& \Pi(N S, I)>\Pi(N I)>\Pi(S, I) \quad \text { if } \quad \frac{4 \Delta^{2}}{9 \sigma}<c<\frac{\Delta^{2}}{2 \sigma}, \\
& \Pi(N I)>\Pi(N S, I)>\Pi(S, I) \quad \text { if } \quad c>\frac{\Delta^{2}}{2 \sigma} .
\end{aligned}
$$

In particular, industry profit always declines if firms exchange their acquired information.

Result 5 can be explained as follows. Information exchange between firms enables them to refine their poaching prices according to the preference of the rivals' customers. Therefore, competition becomes more intense because it forces firms to cut their poaching prices in order to subsidize the switching costs of each group of consumers separately, while at the same time also forcing the firms to adjust their incumbency prices in order to defend their inherited market shares. This economic intuition is essentially based on a mechanism identical to that in Thisse and Vives (1988) which shows that perfect price discrimination intensifies competition compared with uniform pricing. However, in light of Liu and Serfes (2004), the implication of the results in Thisse and Vives (1988) for our setting is not straightforward, because, as Liu and Serfes (2004) show, the profits associated with price discrimination vary nonmonotonically with respect to the precision of information that the firms use as the basis for the price discrimination.

\subsection{Analysis of consumer welfare}

Next, we compute and compare aggregate consumer welfare among the three outcomes. Using the utility function (1), we first calculate the aggregate welfare of consumers with an inherited 
customer relationship with firm $A$.

$$
\begin{aligned}
C W_{A} & =\int_{s_{A}^{H H}}^{1}\left(v_{H}-p_{A}^{H H}\right) d s+\int_{0}^{s_{A}^{H H}}\left(v_{H}-q_{B}^{H H}-\sigma s\right) d s+\int_{s_{A}^{H L}}^{1}\left(v_{H}-p_{A}^{H L}\right) d s+\int_{0}^{s_{A}^{H L}}\left(v_{L}-q_{B}^{H L}-\sigma s\right) d s \\
& +\int_{s_{A}^{L H}}^{1}\left(v_{L}-p_{A}^{L H}\right) d s+\int_{0}^{s_{A}^{L H}}\left(v_{H}-q_{B}^{L H}-\sigma s\right) d s+\int_{s_{A}^{L L}}^{1}\left(v_{L}-p_{A}^{L L}\right) d s+\int_{0}^{s_{A}^{L L}}\left(v_{L}-q_{B}^{L L}-\sigma s\right) d s . \quad(14)
\end{aligned}
$$

The equilibrium prices (6) and (7) and the associated bounds of integration given in (3) should be substituted into (14) in order to calculate the consumer surplus associated with the regime (S,I), that is, the regime with information acquisition and information sharing. The consumer surplus displayed in (14) can be decomposed as follows. The first two terms are the surplus of consumers who have a high preference for both brands. Among this category of consumers the first term is the consumer surplus of those who have high switching costs and therefore stay loyal to brand $A$. The second term is the consumer surplus of those who have low switching costs and therefore respond to firm $B^{\prime}$ s discounted poaching price, $q_{B}^{H H}$.

The third and fourth integrals in (14) characterize the surplus of consumers who have a high valuation for $A$, but a low valuation for $B$. Again, among this category of consumers the third integral is the surplus of those who have high switching costs and therefore stay loyal to brand $A$, whereas the fourth integral is the surplus of those who switch to $B$. The fifth and sixth integrals have a completely analogous interpretation, except that the valuations for the two available brands are reversed. Finally, the seventh and eight integrals capture the surplus of consumers who have low valuations for both brands.

The upper-left quadrant in Table 5 reports the consumer surplus of customers belonging to firm $A^{\prime}$ s segment under circumstances in which both firms acquire and share information. We denote this consumer surplus by $C W_{A}(\mathrm{~S}, \mathrm{I})$. It is computed by substituting the equilibrium prices (6) and (7) into the market share thresholds (3), and then into (14). The lower-left quadrant in Table 5 is the consumer surplus when firms acquire information but do not share it. This outcome is denoted by $C W_{A}(\mathrm{NS}, \mathrm{I})$. It is computed by substituting the equilibrium prices (10) into the market share thresholds (3), and then into (14). Finally, the entries in the right-hand column of 
Table 5 exhibit the consumer surplus of the configuration where neither firm acquires information regarding the consumer-specific preferences of its consumers. We denote this consumer surplus by $C W_{A}(\mathrm{NI})$; it is obtained by substituting the equilibrium prices (8) into the market share thresholds (3), and then into (14). As the right-hand column of Table 5 formally demonstrates, consumer surplus is invariant to whether the firms share information or not if no firm acquires information.

\begin{tabular}{c|c|c|}
\multicolumn{1}{c}{ ACQUIRE INFORMATION (I) } & \multicolumn{2}{c}{ NOT ACQUIRE INFORMATION (NI) } \\
\cline { 2 - 3 } $\mathrm{S}$ & $\frac{\Delta^{2}+18 \sigma\left(v_{H}+v_{L}\right)-22 \sigma^{2}}{9 \sigma}$ & $\frac{9 \Delta^{2}+18 \sigma\left(v_{H}+v_{L}\right)-22 \sigma^{2}}{9 \sigma}$ \\
\cline { 2 - 3 } $\mathrm{NS}$ & $\frac{9 \Delta^{2}+72 \sigma\left(v_{H}+v_{L}\right)-88 \sigma^{2}}{36 \sigma}$ & $\frac{9 \Delta^{2}+18 \sigma\left(v_{H}+v_{L}\right)-22 \sigma^{2}}{9 \sigma}$ \\
\cline { 2 - 3 } &
\end{tabular}

Table 5: Aggregate consumer welfare based on (14) for consumers who have previously purchased brand $A$ under the three possible symmetric outcomes: $C W_{A}(\mathrm{~S}, \mathrm{I}), C W_{A}(\mathrm{NS}, \mathrm{I})$, and $C W_{A}(\mathrm{NI})$.

From Table 5 we can draw the following conclusions.

Result 6. (a) Consumers lose when firms invest in acquiring information about their preferences.

(b) Information sharing further magnifies these losses for consumers.

Formally,

$$
C W_{A}(N I)=C W_{B}(N I)>C W_{A}(N S, I)=C W_{B}(N S, I)>C W_{A}(S, I)=C W_{B}(S, I) .
$$

Result 6 implies that the acquisition and use of information regarding customer-specific preferences as a basis for type-contingent pricing always hurts consumers, independently of the costs of information acquisition. In the absence of any information acquisition, the pricing decisions reflect identity recognition according to the terminology introduced in Shy and Stenbacka (2011). This means that the firms operate with information that facilitates only one incumbency price, applied to customers belonging to their own inherited market segment, and one poaching price, applied to consumers with an inherited customer relationship with the rival. According to Result 6, consumers are always worse off when firms can condition prices directed to their own customers on information about their preferences. In this respect, our model implies that price discrimination 
based on acquired knowledge regarding customer-specific preferences and applied by competing duopolists hurts consumers compared with price discrimination that is based only on identity recognition.

Furthermore, information exchange expands the price instruments available to the firms, because with information exchange the firms can condition poaching prices on the information regarding customer-specific preferences acquired by the rival. According to Result 6, this expansion of the scope of price discrimination hurts consumers mainly because of the increase in the number of customers who switch inefficiently, characterized in Result 4 . This feature is far from self-evident, because information exchange could enhance the utility of consumers who are being targeted with poaching offers. On the other hand, some consumers who stay loyal to their brands may face a price increase as incumbent firms adjust the offers targeted to their own customers when rival firms refine their poaching prices. Result 6 shows that the loss of consumer welfare stemming from adjusted incumbency prices together with excessive switching between brands exceeds the gain to consumers who are approached by more refined poaching offers.

\subsection{Analysis of total welfare}

We conclude this section by computing total welfare, which is defined as the sum of aggregate consumer welfare (consumer surplus) and industry profits. Formally, $W=C W_{A}+C W_{B}+\pi_{A}+\pi_{B}$. Table 6 combines Table 4 and Table 5.

\begin{tabular}{c|c|c|}
\multicolumn{1}{c}{ ACQUIRE INFORMATION (I) } & NOT ACQUIRE INFORMATION (NI) \\
\cline { 2 - 3 } $\mathrm{SS}$ & $\frac{2\left[5 \Delta^{2}+18 \sigma\left(v_{H}+v_{L}\right)-2 \sigma^{2}\right]}{9 \sigma}-2 c$ & $\frac{2\left[9 \Delta^{2}+18 \sigma\left(v_{H}+v_{L}\right)-2 \sigma^{2}\right]}{9 \sigma}$ \\
\cline { 2 - 3 } $\mathrm{NS}$ & $\frac{27 \Delta^{2}+72 \sigma\left(v_{H}+v_{L}\right)-8 \sigma^{2}}{18 \sigma}-2 c$ & $\frac{2\left[9 \Delta^{2}+18 \sigma\left(v_{H}+v_{L}\right)-2 \sigma^{2}\right]}{9 \sigma}$ \\
\cline { 2 - 3 } &
\end{tabular}

Table 6: Total welfare under the three possible symmetric outcomes: (S,I), (NS,I) and (NI).

Table 6 implies the following result.

Result 7. Investments in customer-specific preference recognition reduces total welfare, and information 
sharing further magnifies the reduction in total welfare. Formally,

$$
W(N I)>W(N S, I)>W(S, I) .
$$

Comparing Result 7 with Result 6 reveals that the ranking of outcomes according to total welfare is aligned with the ranking according to consumer welfare. This follows from Result 4, which identifies the source of the distortion as inefficient switching to a less-preferred brand.

However, comparing Result 7 with Result 5 reveals that the rankings associated with total welfare and industry profit are aligned only if the cost of information acquisition is sufficiently high, $c>\Delta^{2} /(2 \sigma)$, in which case firms do not invest in information.

For intermediate cost levels, $4 \Delta^{2} /(9 \sigma)<c<\Delta^{2} /(2 \sigma)$, there are two cases. In the absence of information sharing, information acquisition stimulates industry profits while reducing consumer welfare. As Result 7 makes clear, the effects on consumer surplus dominate the effects on profit incentives, so total welfare declines. In the presence of information sharing, information acquisition reduces both industry profits and consumer welfare.

Finally, for sufficiently low costs of information acquisition, $c<4 \Delta^{2} /(9 \sigma)$, information acquisition always promotes industry profits and reduces consumer surplus. Again, Result 7 shows that the loss of consumer welfare from information acquisition dominates the corresponding gain in industry profit.

\section{Strategic Information Sharing}

Our analysis so far has relied on exogenous decisions regarding the exchange of information between the firms. This section extends the previous analysis by integrating each firm's decision whether to share information with the overall strategic plan of the firms. Formally, this section characterizes the subgame-perfect equilibria (SPE) of the following three-stage game: ${ }^{3}$

Stage I: Each firm decides whether to share its customer-related information with the rival firm

(S), or not to share (NS). Sharing (or not sharing) information is assumed to be costless.

\footnotetext{
${ }^{3}$ The results are robust to reordering stages I and II. The reason we chose to follow this particular order is our desire to explore the effect of information exchange on the incentives to invest in customer recognition.
} 
Stage II: Each firm decides whether to invest (I) at cost $c$, or not invest (NI), in learning the preferences of its customers.

Stage III: Each firm chooses its brand prices based on the available information regarding customerspecific preferences to maximize profit, defined in (4) and (5).

Sections 3 and 4 computed the equilibria for the subgames described as Stage II and Stage III above. These derivations were based on the assumption that both firms adopt the same information sharing policy in which either both firms exchange information or both conceal their known information. In order to compute the SPE associated with the inclusion of Stage I into the game, we must also compute the equilibria for Stage II and Stage III, assuming asymmetric decisions with respect to information sharing.

\subsection{Asymmetric information sharing}

Assume now without loss of generality that firm $A$ shares its information with firm $B$, but that firm $B$ conceals its information from $A$. We denote this outcome by (S, NS). The outcome (NS, S) is similarly defined by reversing the roles of firm $A$ and $B$. Table 7 displays the profits associated with the information investment decisions made by the firms for the asymmetric configuration (S, NS) with respect to information sharing. The upper-left profits in Table 7 are the same as

Firm $B$

\begin{tabular}{|c|c|c|c|c|c|}
\hline \multirow[b]{3}{*}{ Firm } & \multirow{3}{*}{ Not INVEST } & \multicolumn{2}{|c|}{ NOT INVEST (NI) } & \multicolumn{2}{|c|}{ INVEST (I) } \\
\hline & & $20 \sigma$ & $20 \sigma$ & $20 \sigma$ & $9 \Delta^{2}+40 \sigma^{2}$ \\
\hline & & $\overline{9}$ & $\overline{9}$ & $\overline{9}$ & $\overline{18 \sigma}$ \\
\hline$A$ & INVEST & $\frac{2\left(\Delta^{2}+10 \sigma^{2}\right)}{9 \sigma}-c$ & $\frac{2\left(\Delta^{2}+10 \sigma^{2}\right)}{9 \sigma}$ & $\frac{2\left(\Delta^{2}+10 \sigma^{2}\right)}{9 \sigma}-c$ & $\frac{13 \Delta^{2}+40 \sigma^{2}}{18 \sigma}-c$ \\
\hline
\end{tabular}

Table 7: Investment in own customer recognition: Profits when firm $A$ shares information with $B$, but $B$ does not share with $A$, (S,NS).

in Tables 1 and 2, because firms do not have any information to share if they do not invest in information acquisition. The profits in the lower-left quadrant of Table 7 are identical to those in Table 1, because it is irrelevant whether or not firm $B$ shares information if firm $B$ does not invest in information. The profits in the upper-right quadrant are copied from Table 2, because firm $A$ 
does not invest and hence has no information to share.

It remains to compute the profits in the lower-right quadrant of Table 7. This is the combination in which both firms invest in learning the preferences of their customers, but only $A$ shares its information with $B$. This allows firm $B$ to free-ride on $A^{\prime}$ 's investment in customer recognition, whereas firm $A$ does not obtain any information regarding $B^{\prime}$ s customers. With full information regarding $A^{\prime}$ s customers, firm $A$ sets type-contingent prices $p_{A}^{H H}, p_{A}^{H L}, p_{A}^{L H}, p_{A}^{L L}$. Likewise, with information sharing firm $B$ targets type-contingent poaching prices $q_{B}^{H H}, q_{B}^{H L}, q_{B}^{L H}, q_{B}^{L L}$ to $A^{\prime}$ s customers. For customers belonging to $B^{\prime}$ s segment, firm $A$ sets a uniform poaching price $q_{A}$, because it has no information about $B^{\prime}$ s customers. Firm $B$ learns its customers' preferences and therefore sets type-contingent prices $p_{B}^{H H}, p_{B}^{H L}, p_{B}^{L H}$, and $p_{B}^{L L}$. Thus, firm $A$ sets five prices whereas firm $B$, which has more information, operates with eight prices. Substituting these prices into (3) and then into the profit functions (4) and (5), the Nash-Bertrand equilibrium prices are found to be

$$
\begin{array}{r}
p_{A}^{H H}=p_{B}^{H H}=p_{A}^{L L}=p_{B}^{L L}=\frac{2 \sigma}{3}, q_{A}=q_{B}^{H H}=q_{B}^{L L}=\frac{\sigma}{3}, p_{A}^{H L}=\frac{\Delta+2 \sigma}{3}, p_{B}^{H L}=\frac{4 \sigma-3 \Delta}{6}, \\
p_{A}^{L H}=\frac{2 \sigma-\Delta}{3}, p_{B}^{L H}=\frac{3 \Delta+4 \sigma}{6}, q_{B}^{H L}=\frac{\sigma-\Delta}{3}, \text { and } q_{B}^{L H}=\frac{\Delta+\sigma}{3} .
\end{array}
$$

Substituting (17) into (4) and (5) yields the equilibrium profits in the lower-right quadrant of Table 7. From this table we can generate the following conclusions.

Result 8. Suppose that firm $A$ shares its available customer-specific information with firm $B$, but that firm $B$ does not share information with firm $A,(S, N S)$. If the cost of acquiring information, $c, i s$ :

(a) low $\left(c<2 \Delta^{2} /(9 \sigma)\right)$, then both firms invest in learning their customers' preferences;

(b) intermediate $\left(2 \Delta^{2} /(9 \sigma) \leq c \leq \Delta^{2} /(2 \sigma)\right)$, then firm $A$ does not invest, whereas firm $B$ invests;

(c) high $\left(c>\Delta^{2} /(2 \sigma)\right)$, then neither firm invests in acquiring customer preference information.

Results 8.a and 8.c are identical to Results 3.a and 3.c. Regardless of whether and how firms share their information, high costs retard information acquisition, whereas low costs promote information acquisition. However, for intermediate costs of information acquisition, 8.b is unique and quite interesting, because the firms adopt different investment strategies. More precisely, it is unprofitable for firm $A$ to invest in information acquisition, because it is committed to sharing the 
information it collects with firm $B$, thereby giving firm $B$ a strategic advantage. Therefore, firm $A$ chooses not to invest. In contrast, in this configuration, firm $B$ invests, because it has exclusive access to the information it collects, as this is not shared with firm $A$.

\subsection{Equilibrium information sharing}

We are now ready to solve Stage I of the game. This involves characterizing the firms' decisions whether or not to share information. Result 8.c demonstrates that firms do not invest when the cost of information acquisition is high. Therefore, for this cost range, the decision whether to share information is irrelevant, because neither firm has any information to share. Thus, it remains to compute the equilibria for low and intermediate acquisition costs.

Result 1, Result 2, and Result 8 all state that both firms invest in acquiring information when the cost is low, $c<2 \Delta^{2} /(9 \Delta)$, independently of whether the firms do or do not share information. Thus, Table 8 gathers the profit levels from the lower-right quadrants of Table $1(\mathrm{~S}, \mathrm{~S})$, Table 2 (NS,NS), and Table 7 (S,NS) and (NS,S).

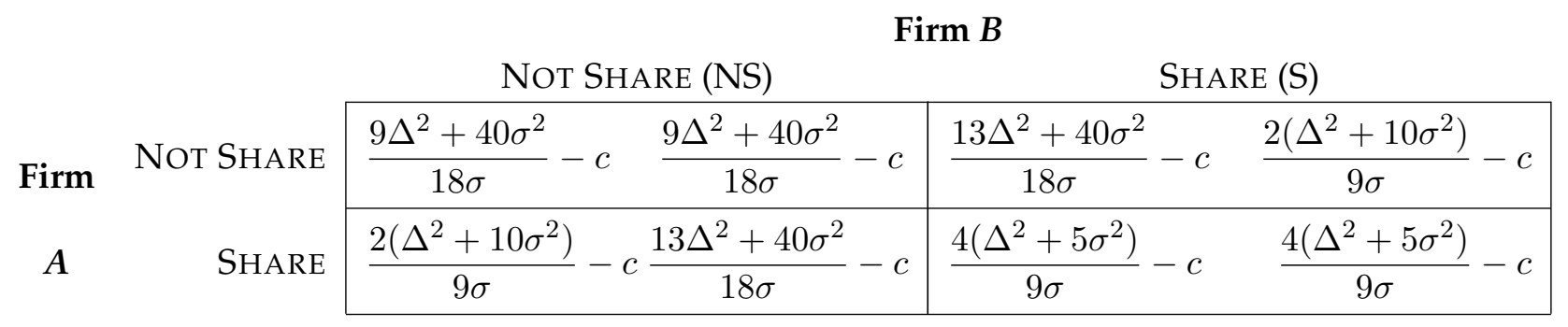

Table 8: Profits for different combinations with respect to the information sharing decisions: The low cost case $\left(c<2 \Delta^{2} /(9 \sigma)\right)$.

For intermediate costs of information acquisition $\left(2 \Delta^{2} /(9 \sigma)<c<\Delta^{2} /(2 \sigma)\right)$, Result 1 states that firms do not invest when information is shared. Result 2 states that firms invest in information acquisition when information is not shared. Result 8 states that the firm that shares information does not invest, whereas the firm that conceals its information invests. Therefore, the quadrant $(\mathrm{S}, \mathrm{S})$ in Table 9 is copied from upper-left quadrant of Table 1. The quadrant (NS,NS) in Table 9 is identical to the lower-right quadrant of Table 2. The profit associated with the (S,NS) quadrant is calculated in the upper-right quadrant of Table 7. Finally, the payoffs under (NS,S) reverse the 
roles of $A$ and $B$ in (S,NS).

Firm $B$

\begin{tabular}{|c|c|c|c|c|c|}
\hline \multirow[b]{2}{*}{ Firm } & \multirow[b]{2}{*}{ NOT SHARE } & \multicolumn{2}{|c|}{ NOT SHARE (NS) } & \multicolumn{2}{|c|}{ SHARE (S) } \\
\hline & & $\frac{9 \Delta^{2}+40 \sigma^{2}}{18 \sigma}-c$ & $\frac{9 \Delta^{2}+40 \sigma^{2}}{18 \sigma}-c$ & $\frac{9 \Delta^{2}+40 \sigma^{2}}{18 \sigma}-c$ & $\frac{20 \sigma}{9}$ \\
\hline$A$ & SHARE & $\frac{20 \sigma}{9}$ & $\frac{9 \Delta^{2}+40 \sigma^{2}}{18 \sigma}-c$ & $\frac{20 \sigma}{9}$ & $\frac{20 \sigma}{9}$ \\
\hline
\end{tabular}

Table 9: Profits for different combinations with respect to the information sharing decisions: The intermediate cost case $\left(2 \Delta^{2} /(9 \sigma)<c<\Delta^{2} /(2 \sigma)\right)$.

Simple comparisons of the profit levels in Table 8 and separately in Table 9 show that neither firm $A$ nor firm $B$ can increase its profits by unilaterally deviating from the outcome (NS,NS). Therefore, the strategy combination (NS,NS) is the unique equilibrium. ${ }^{4}$

Result 9. The strategy combination where both firms decide not to share information in the first stage supports a unique SPE equilibrium for the three-stage game.

Result 9 implies that in the three-stage game, the analysis given in Section 4 characterizes the investments in information acquisition and equilibrium prices and profits, which are consistent with the subgame perfect equilibrium. This holds true, because Section 4 assumes that firms do not share information. Thus, in the full game, Result 2 applies.

In light of Result 9, our theoretical model supports as an empirical hypothesis that firms do not engage in information exchange regarding information about customer-specific preferences. And, indeed, in many industries we do not observe firms' applying such practices. Nevertheless, the exchange of customer-specific information is a central feature of some key industries such as banking and insurance. Does this evidence contradict the predictions of our model? No, because our model does not incorporate some of the key features associated with these particular industries. For example, Padilla and Pagano (2000) focus on a lending industry characterized by moral

\footnotetext{
${ }^{4}$ Result 9 is robust to reversing the order of Stages I and II. That is, firms would not share information if this decision were made after they had acquired customer-specific information. An extension of this model could also incorporate such reversed timing in conjunction with a commitment by firms to make the sharing decision contingent on the information they receive.
} 
hazard and demonstrates how banks have an incentive to engage in borrower-specific information exchange as a disciplinary device with the effect of increasing the incentives for borrowers to exert effort in order to avoid bankruptcy. Likewise, in credit markets characterized by adverse selection, information exchange regarding individual borrowers makes it possible for banks to avoid granting funding to projects that are not creditworthy, thereby promoting banks' profits by reducing credit losses. Our study demonstrates that the arguments justifying the adoption of customerspecific information exchange cannot be generalized to industries where the particular features of adverse selection or moral hazard are absent.

We conclude with a welfare evaluation of the market allocations generated within the framework of the three-stage game by comparing Result 9 with Result 7 . Recall that Result 7 ranks outcomes according to total welfare so that $W(\mathrm{NI})>W(\mathrm{NS}, \mathrm{I})>W(\mathrm{~S}, \mathrm{I})$. Hence,

Result 10. From the point of view of total welfare:

(a) the equilibrium with no sharing of information is efficient;

(b) the equilibrium with no investment in information acquisition is efficient for high investment costs $\left.\left.\left(c<\Delta^{2} /\right) 2 \sigma\right)\right)$;

(c) the equilibrium with investment in information acquisition is inefficient for low investment costs ( $c<$ $\left.\Delta^{2} /(2 \sigma)\right)$.

Within the framework of our model we can conclude that the market equilibrium is always consistent with social efficiency as far as the decision regarding information sharing is concerned. It should be emphasized that this conclusion is reached under circumstances where information exchange is given no role as a device that could potentially facilitate the extraction of consumer surplus through mechanisms such as (tacit) collusion (see Kühn 2001). Incorporating such mechanisms would tend to further strengthen the favorable welfare implications associated with no information sharing.

As for information acquisition, Result 10 states that the market equilibrium supports efficient investment decisions as long as the costs of information acquisition are high. However, for low costs of information acquisition Result 10 identifies a market failure with excess investment in information acquisition. 


\section{Policy Implications and Directions for Future Research}

In this study we have investigated the effects of costly acquisition and exchange of customerspecific information on industry profits and consumer welfare. We have shown that consumers are hurt when firms acquire information about their preferences and that information sharing between firms further magnifies these losses for consumers. We have found that no information sharing supports a subgame perfect equilibrium and that this equilibrium is also efficient. Finally, we have demonstrated that equilibrium investments in customer information may be excessive if firms bear low costs of acquiring customer-specific information.

Firms value the informational advantage associated with learning their customers' preferences. Our analysis implies that a firm has no incentive to give up this advantage through information exchange even though such an exchange would extend the information of consumer-specific preferences to cover the rival's customers. A central reason for this conclusion is that information exchange intensifies competition.

Our analysis implies that information exchange among firms is not likely to be observed in industries satisfying the general features covered by our model. Still, information exchange is observed in some industries, such as banking and insurance. Indeed, as studies focusing on these industries emphasize, information exchange can be profit-enhancing as well as an efficient mechanism to overcome significant problems associated with moral hazard and adverse selection under circumstances where some types of consumers may cause firms to suffer severe losses. However, as our general analysis suggests, information exchange is typically an inefficient practice unless such industry-specific conditions prevail. In addition, firms have no incentive to engage in this practice.

These arguments hold true under the assumption that firms engage in noncooperative price competition. Information exchange may very well serve as a device to facilitate tacit or explicit collusion. These findings suggest a policy conclusion that there is merit in monitoring the exchange of customer-specific information and having antitrust authorities challenge it when warranted. However, firms engaging in the practice of exchanging customer-specific information should be given the opportunity to present arguments for efficiency enhancement associated with 
information exchange and should bear the burden of proving these arguments.

Our study identifies only one potential market failure when firms invest in information at low cost and adjust prices accordingly. Under such circumstances the loss to consumers outweighs the gains in industry profits. However, this result by itself seems insufficient to warrant restrictions on information acquisition, because firms may have to reward consumers for revealing information about themselves. Rewards can be granted in the form of points or discounts on future purchases. Indeed, we can interpret the cost parameter, $c$, as including the costs associated with such customer loyalty programs, but our model does not capture the process by which consumers respond to such programs. Future research could enrich our model by incorporating mechanisms for how strategic customers reveal information regarding their types.

In order to be able to highlight the central economic mechanisms in a transparent way, our model makes a number of simplifying assumptions. The robustness of the results can be questioned in light of the generality of these assumptions. In this respect, our model suggests at least the following questions as topics for future research: To what extent are the results robust to an alteration of the cost structure of information acquisition, such as increasing marginal cost with respect to the number of own customers? Following the literature on information exchange, we have assumed that firms reveal their information in a truthful way. It would be interesting to examine whether the model can be extended to capture strategic information exchange. Finally, it should be emphasized that our analysis has not incorporated behavioral aspects, according to which the collection and exchange of customer-specific information could potentially induce consumers to modify their behavior in attempts to, for example, defend individual privacy. To incorporate such features our model could be extended to include elements from behavioral economics.

\section{References}

Brown, M., T. Jappelli, and M. Pagano. 2009. “Information sharing and credit: Firm-level evidence from transition countries." Journal of Financial Intermediation 18(2): 151-172.

Chen, Y. 1997. "Paying Customers to Switch." Journal of Economics and Management Strategy 6(4): 877-897. 
Chen, Y., C. Narasimhan, and Z. Zhang. 2001. "Individual marketing with imperfect targetability." Marketing Science 23-41.

Chen, Y., and Z. Zhang. 2009. "Dynamic Targeted Pricing with Strategic Consumers." International Journal of Industrial Organization 27(1): 43-50.

Esteves, R. 2009. “A Survey on the Economics of Behaviour-Based Price Discrimination." NIPE Working Paper 5/2009.

Esteves, R. 2010. “Pricing with Customer Recognition." International Journal of Industrial Organization 28(6): 669-681.

Fudenberg, D., and J. Tirole. 2000. "Customer Poaching and Brand Switching." RAND Journal of Economics 31(4): 634-657.

Fudenberg, D., and M. Villas-Boas. 2007. “Behavior-Based Price Discrimination and Customer Recognition." In Handbook of Economics and Information Systems, ed. T. Hendershott, 377-433. Elsevier.

Gabrielsen, T. 2004. "Customer Poaching with Differentiated Products and Switching Costs." Working Paper, University of Bergen.

Gal-Or, E. 1985. "Information Sharing in Oligopoly." Econometrica 53(2): 329-343.

Gal-Or, E. 1986. "Information Transmission-Cournot and Bertrand Equilibria." Review of Economic Studies 53(1): 85-92.

Ganuza, J., and J. Jansen. 2010. “Too Much Information Sharing? Welfare Effects of Sharing Acquired Cost Information in Oligopoly." SSRN eLibrary.

Gehrig, T., O. Shy, and R. Stenbacka. 2011. "History-based Price Discrimination and Entry in Markets with Switching Costs: A Welfare Analysis." European Economic Review 55(5): 732-739.

Gehrig, T., and R. Stenbacka. 2004. "Differentiation-induced Switching Costs and Poaching." Journal of Economics and Management Strategy 13(4): 635-655. 
Gehrig, T., and R. Stenbacka. 2007. "Information Sharing and Lending Market Competition with Switching Costs and Poaching." European Economic Review 51(1): 77-99.

Jansen, J. 2008. "Information acquisition and strategic disclosure in oligopoly." Journal of Economics $\mathcal{E}$ Management Strategy 17(1): 113-148.

Jappelli, T., and M. Pagano. 2002. “Information sharing, lending and defaults: Cross-country evidence." Journal of Banking E Finance 26(10): 2017-2045.

Kirby, A. 2004. "The product market opportunity loss of mandated disclosure." Information Economics and Policy 16(4): 553-577.

Kühn, K. 2001. "Fighting Collusion by Regulating Communication Between Rirms." Economic Policy 16(32): 167-204.

Liu, Q., and K. Serfes. 2004. "Quality of information and oligopolistic price discrimination." Journal of Economics \& Management Strategy 13(4): 671-702.

Liu, Q., and K. Serfes. 2006. “Customer information sharing among rival firms.” European Economic Review 50(6): 1571-1600.

Padilla, A., and M. Pagano. 1997. "Endogenous Communication Among Lenders and Entrepreneurial Incentives." Review of Financial Studies 10(1): 205.

Padilla, A., and M. Pagano. 2000. "Sharing Default Information as a Borrower Discipline Device." European Economic Review 44(10): 1951-1980.

Pagano, M., and T. Jappelli. 1993. "Information Sharing in Credit Markets." The Journal of Finance 48(5): 1693-1718.

Shapiro, C. 1986. "Exchange of Cost Information in Oligopoly." Review of Economic Studies 53(3): 433-446.

Shin, J., and K. Sudhir. 2010. “A Customer Management Dilemma: When is it Profitable to Reward One's Own Customers?" Marketing Science 29(4): 671-689. 
Shy, O., and R. Stenbacka. 2011. "Customer Recognition and Competition." Federal Reserve Bank of Boston, Research Department Working Paper No. 11-7.

Taylor, C. 2003. "Supplier Surfing: Competition and Consumer Behavior in Subscription Markets." RAND Journal of Economics 34(2): 223-246.

Thisse, J., and X. Vives. 1988. "On the Strategic Choice of Spatial Price Policy." The American Economic Review 78(1): 122-137. 